\title{
Cystine accumulation in cystinotic fibroblasts from free and protein-linked cystine but not cysteine
}

\author{
Jess G. THOENE and Rosemary M. LEMONS \\ Department of Pediatrics, University of Michigan School of Medicine, Ann Arbor, MI 48109, U.S.A.
}

(Received 27 July 1982/Accepted 16 September 1982)

\begin{abstract}
The accumulation of cystine in cystinotic fibroblasts from free and protein-linked cystine has been investigated. Cystine is not accumulated from cysteine but is readily accumulated from cystine. The accumulation from free cystine does not occur as a result of pinocytosis or from the degradation of a rapidly metabolized protein pool. Further studies of the degradation of disulphide-containing proteins by these cells may aid understanding of the mechanisms of proteolysis.
\end{abstract}

Nephropathic cystinosis is an autosomal recessive disease characterized by intralysosomal cystine accumulation (Schulman et al., 1969). The cause of the cystine storage has recently been defined as a specific defect in the lysosomal transport of cystine (Gahl et al., 1982a,b; Jonas et al., 1982). We have previously shown that fibroblasts derived from individuals with cystinosis are depleted of their cystine content by incubation in medium containing cysteamine or phosphocysteamine (Thoene et al., 1976; Thoene \& Lemons, 1980a). Subsequently, it has been shown that cystine reaccumulates, in part, from the degradation of endogenous proteins (Thoene et al., 1977) and that the cystine content can be modulated by supplementation of the culture medium with a disulphide-rich protein, bovine serum albumin (Thoene \& Lemons, 1980b). The question of whether only cystine or both cystine and cysteine residues in proteins contribute to cystine storage remained unanswered. The current investigations show that only cystine, but not cysteine, is retained in the lysosomal compartment. These results apply to both free and protein-linked cystine and cysteine. They agree with those of Gahl et al. $(1982 a, b)$, who showed that cystine exits from normal lysosomes as cystine, and that cysteine exits passively from both normal and cystinotic lysosomes. These findings raise further questions about the route by which free cystine enters the lysosomal pool to avoid reduction to cysteine via GSH and various cellular reductases. The results further suggest that cystinotic fibroblasts may be a useful system for studies on the mechanism of degradation of disulphide-containing proteins,

Abbreviation used: GSH, reduced glutathione.
Part of this work was presented at the Annual Meeting of the American Society of Human Genetics held in Dallas, TX, U.S.A. in 1981.

\section{Experimental}

\section{Materials}

The cystine- and cysteine-containing proteins were obtained from Sigma and used without further purification. The cystine-binding protein used in the cystine assays was a gift from Dr. Jerry A. Schneider (Department of Pediatrics, University of California School of Medicine, La Jolla, CA, U.S.A.). Radiochemicals ( ${ }^{125} \mathrm{I}$-labelled bovine serum albumin, ${ }^{125}$ I-labelled insulin, $\left[{ }^{35} \mathrm{~S}\right]-$ and $\left[{ }^{14} \mathrm{C}\right]-$ cystine) were purchased from New England Nuclear Corp. All other chemicals were the best available reagent grade and purchased from Calbiochem, Sigma, or Pierce Chemical Co.

\section{Methods}

Diploid epithelial fibroblasts were grown from skin biopsies from patients with nephropathic cystinosis or purchased from the Human Genetic Mutant Cell Repository. They were cultured in a modified Ham's $\mathrm{F}_{12}$ medium supplemented with $10 \%$ $(\mathrm{v} / \mathrm{v})$ foetal-bovine serum and incubated at $37^{\circ} \mathrm{C}$ in a humidified incubator flushed with an air $/ \mathrm{CO}_{2}$ $(19: 1)$ mixture. Cystine-free medium was the same medium with cystine deleted. Cells were harvested by trypsin treatment and immediately broken by sonic disruption in $5 \mathrm{mM}-N$-ethylmaleimide $/ 100 \mathrm{~mm}$ phosphate buffer, pH 7.4. Cell proteins were precipitated by centrifugation after addition of $3 \%(\mathrm{v} / \mathrm{v})$ sulphosalicylic acid and the supernatant removed for analysis either by one-dimensional high-voltage electrophoresis on paper ([$\left.{ }^{35} \mathrm{~S}\right]$ cystine studies) 
(Thoene et al., 1976) or by cystine determination via the cystine-binding-protein assay (Oshima et al., 1974). Intracellular horseradish peroxidase accumulation was determined by the $o$-dianisidine method after incubation in test medium supplemented with $1 \mathrm{mg}$ of horseradish peroxidase $/ \mathrm{ml}$ (Steinman et al., 1974). Cell number was determined by a Coulter counter model $\mathrm{Z}_{\mathrm{F}}$, and cell protein by Lowry's method (Lowry et al., 1951). Radioactivity in the cell supernatant was quantified by counting a sample in Aquasol (New England Nuclear) in a Beckman LS-100 liquid-scintillation counter. Degradation of ${ }^{125}$ I-labelled proteins was determined by measuring the increase in acid-soluble ${ }^{125}$ I radioactivity appearing in the medium at each time point in a Tracor gamma counter (Thoene \& Lemons, 1980b). Cystine-depleted cystinotic fibroblasts were prepared by incubation in cystine-free medium containing $1.0 \mathrm{~mm}$-cysteamine (2-aminoethanethiol) for 30 or $60 \mathrm{~min}$ (Thoene et al., 1976).

\section{Results}

The effect of a variety of predominantly cystinerich or cysteine-rich proteins on cystine accumulation in cystinotic fibroblasts is shown in Table 1. Confluent cultures of cystinotic fibroblasts were depleted of their initial cystine content by treatment with cysteamine, washed with phosphate-buffered saline (containing, in $\mathrm{g}$ /litre: $\mathrm{CaCl}_{2}, 0.1 ; \mathrm{KCl}, 0.2$; $\mathrm{KH}_{2} \mathrm{PO}_{4}, 0.2 ; \mathrm{MgCl}_{2}, 6 \mathrm{H}_{2} \mathrm{O}, 0.1 ; \mathrm{NaCl}, 8.0$; $\mathrm{NaH}_{2} \mathrm{PO}_{4}, 7 \mathrm{H}_{2} \mathrm{O}, 2.16$ ), $\mathrm{pH} 7.4$, then replaced in cystine-free medium with foetal-calf serum, supplemented with the test protein at the indicated concentration. After a $24 \mathrm{~h}$ incubation, the cells were harvested by trypsin treatment and the intracellular cystine content determined by the cystine-binding protein assay.

It is seen that, compared with control cells incubated in cystine-free medium lacking any protein supplementation, the cystine-rich proteins $(a)$ uniformly produced increased cystine accumulation $(109-425 \%)$, whereas the cysteine-rich proteins $(b)$ inhibited cystine accumulation (14-121\%). Cystine accumulation in the control cells under these conditions is the result of endogenous proteolysis (Thoene et al., 1977) and varies with cell line and from day to day within the same cell line. After $24 \mathrm{~h}$ incubation in cystine-free, serum-free medium, the mean cystine content of six cell lines measured a total of 11 times was $0.52 \pm 0.28 \mathrm{nmol} / 10^{6}$ cells (range $0.22-1.03$ ). This variability accounts for the wide standard deviations shown in Table 1 when the cystine accumulation is expressed as '\% of control'.

To control for variation in the rates of proteolysis, similar studies were performed comparing the amount of cystine accumulation produced with the amount of protein degraded using ${ }^{125}$ I-labelled proteins. Our prior work (Thoene \& Lemons,
$1980 b$ ) has demonstrated that cystinotic fibroblasts accumulate cystine from the degradation of bovine serum albumin in a concentration-dependent manner. The correlation coefficient for the relationship between bovine serum albumin degradation and cystine accumulation was found to be 0.97 . A similar result has been found to exist when insulin is the test protein. ${ }^{125} \mathrm{I}$-labelled insulin in concentrations of 1.0 or $0.1 \mathrm{mg} / \mathrm{ml}$ was added to cultures of cystine-depleted cystinotic fibroblasts and both intracellular cystine accumulation and ${ }^{125}$ I-labelled insulin degradation measured. The results are shown in Figs. 1 and 2. There is a clear increase in the amount of cystine that accumulates in the presence of insulin compared with control cells; however, the cystine accumulation is not well correlated with insulin concentration (cf. Table 1). The correlation between the amount of insulin degraded and the amount of cystine accumulated is 0.81 (Fig. 2), which is less than that found with bovine serum albumin (0.97). These discrepancies probably result from saturation of insulin receptors on the cell surface during the first few hours of incubation, leading to down-regulation and to slowing of the rate of entry to the basal pinocytosis rate (King et al., 1980). The dose-dependence and correlation between bovine serum albumin degradation and cystine accumulation is better, presumably because bovine serum albumin lacks a specific cell-surface receptor.

Opposite results were found when the degradation of thiol-rich proteins was measured. The results in Fig. 3 show that reduced bovine serum albumin, prepared by reaction with $0.3 \mathrm{M}$-mercaptoethanol, followed by extensive dialysis under $\mathrm{N}_{2}$, was degraded twice as rapidly as the native preparation not subjected to disulphide reduction (Fig. $3 b$ ). However, little cystine accumulation was produced (Fig. 3c), even after the reduced preparation had re-oxidized to $90 \%$ disulphide state, as determined by reaction of portions of the test medium with Ellman's reagent (Fig. $3 a$ ).

A similar result was found when the cystine accumulation produced by native (oxidized) bovine serum albumin was compared with that produced by ovalbumin (Fig. 4). Ovalbumin contains $4 \mathrm{~mol}$ of cysteine and $1 \mathrm{~mol}$ of cystine per mol of protein. Less cystine accumulation was found in ovalbuminexposed cells than in control cells placed in medium lacking protein, even though an amount of ovalbumin containing $71 \mathrm{nmol}$ of cysteine and $18 \mathrm{nmol}$ of cystine was degraded during the $24 \mathrm{~h}$ incubation. The relatively small increment in cystine accumulation produced by bovine serum albumin in this experiment is because of the low concentration used $(10.0 \mathrm{mg} / \mathrm{ml}$; see Table 1$)$.

To determine if the same phenomenon exists with respect to free (non-protein) cystine, the effect of free 
cystine and cysteine on intracellular cystine accumulation was examined. Cystine-depleted cystinotic fibroblasts reaccumulate cystine at a rate proportional to the concentration of free cystine in the culture medium (Fig. 5). Since cystine entry into the lysosomal pool is presumably a multi-step process, traditional uptake kinetics may not apply. However, the data permit calculation of a concentration half-saturating the entry of $67 \mu \mathrm{M}$ and a maximum rate of entry of approx. $0.7 \mathrm{nmol}$ of

Table 1. Effect of cystine-rich or cysteine-rich proteins on intracellular cystine accumulation Confluent cultures of cystinotic fibroblasts were depleted of intracellular cystine by treatment for $1 \mathrm{~h}$ with $1.0 \mathrm{~mm}$ cysteamine, washed with phosphate-buffered saline, and replaced in cystine-free medium containing the test protein at the indicated concentration. After $24 \mathrm{~h}$ incubation at $37^{\circ} \mathrm{C}$, the cells were harvested by trypsin treatment and the intracellular free cystine content quantified via a cystine-binding protein assay. 'Cystine ratio (\% of control)' refers to the ratio of cystine found in the test plates to that found in control plates incubated in the absence of protein. Data shown are the means for duplicate plates. Under 'Reduced albumin (i)' in $(b)$ the bovine serum albumin was artificially reduced (produced by exposure to $0.3 \mathrm{M}$-mercaptoethanol in $6 \mathrm{M}$-urea for $2 \mathrm{~h}$, followed by $48 \mathrm{~h}$ dialysis under $\mathrm{N}_{2}$ ); it is rapidly reoxidized when added to tissue culture. The initial thiol content was approx. $50 \%$ (i.e. $9 \mathrm{~mol}$ of SS $/ 8 \mathrm{~mol}$ of SH). In this experiment 'Cystine ratio' is the ratio of cystine found in cells treated with the reduced protein to that found in those treated with the native protein. Statistical analysis of mean cystine content of treated cells versus control cells by Student's one-tailed $t$-test. Bovine serum albumin: $25 \mathrm{mg} / \mathrm{ml}, P=0.012 ; 10 \mathrm{mg} / \mathrm{ml}, P=0.07$. Insulin: $1.0 \mathrm{mg} / \mathrm{ml}, P=0.05 ; 0.1 \mathrm{mg} / \mathrm{ml}, P=0.10$. Ovalbumin: $25 \mathrm{mg} / \mathrm{ml}, P=0.12$. Reduced albumin, $10 \mathrm{mg} / \mathrm{ml}: P<0.15$. Abbreviations used: BSA, bovine serum albumin; RNAase, ribonuclease.

(a) Cystine-rich proteins

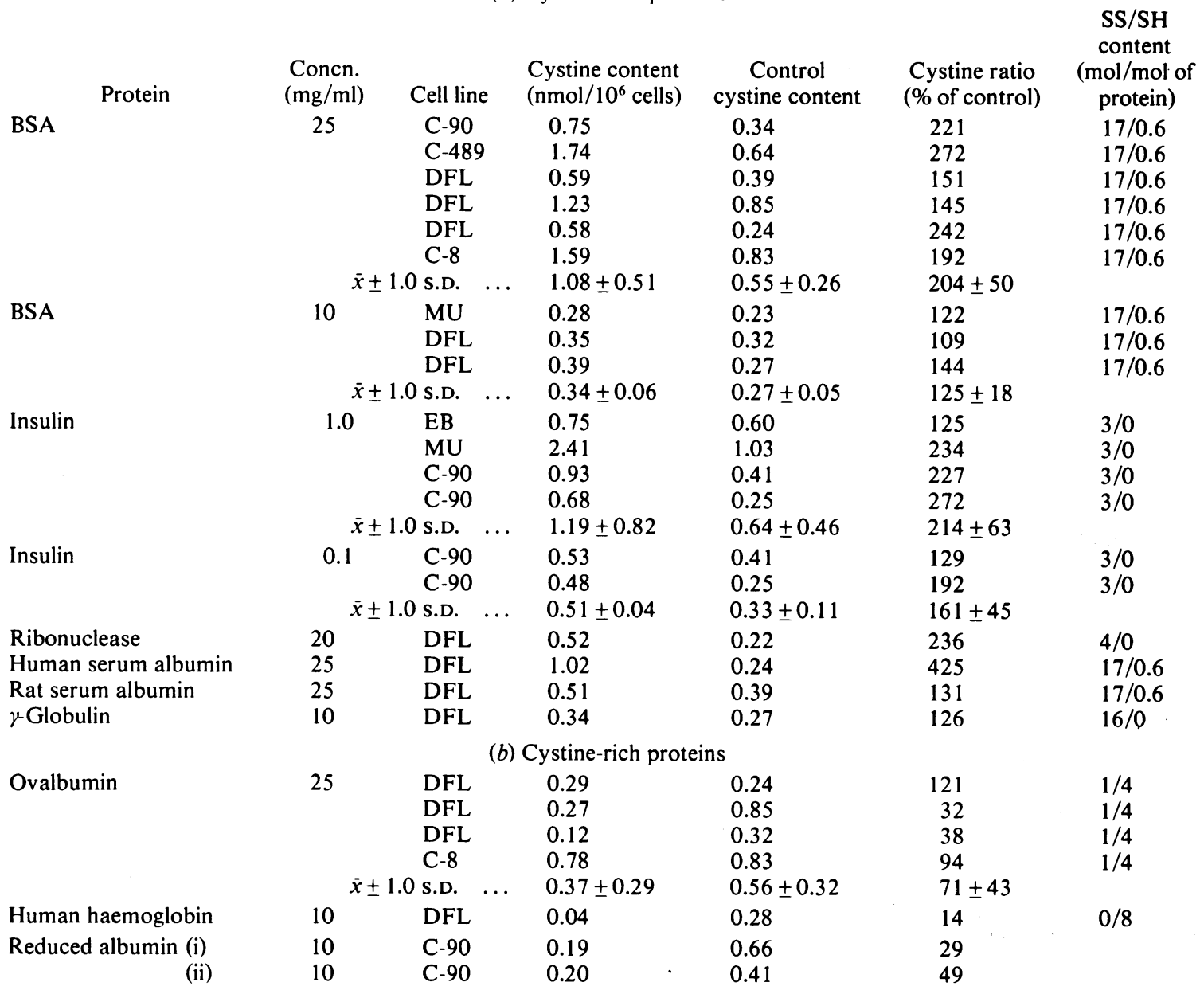




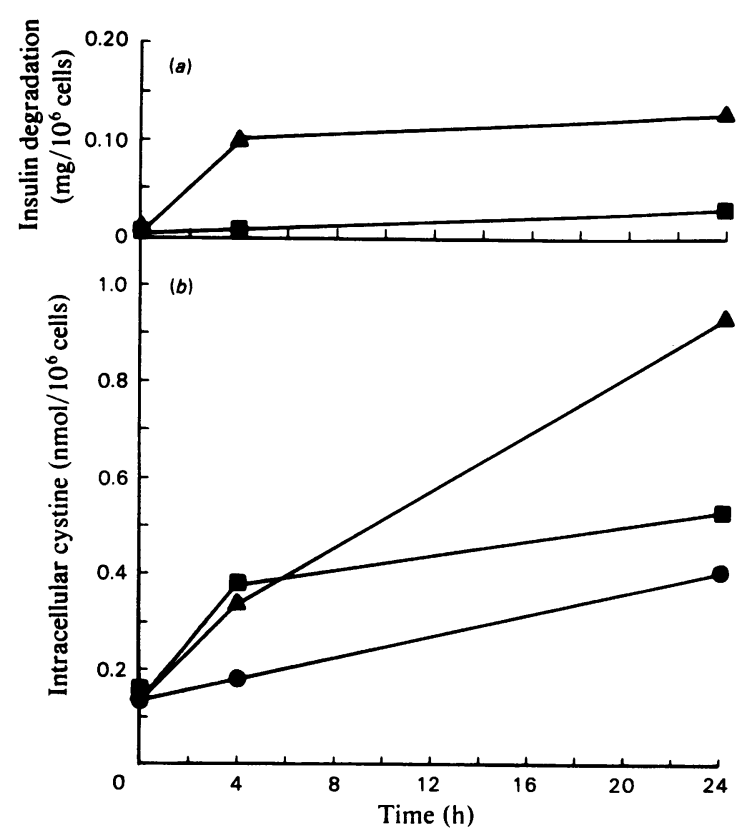

Fig. 1. Effect of bovine insulin on cystine accumulation by cystine-depleted cystinotic fibroblasts incubated in cystine-free medium

$\Delta, 1.0 \mathrm{mg}$ of insulin/ml (sp. radioactivity $2.39 \times$ $10^{5}$ c.p.m. $/ \mathrm{mg}$ ); $0.1 \mathrm{mg}$ of insulin $/ \mathrm{ml}$ (sp. radioactivity $2.34 \times 10^{6}$ c.p.m./mg); $\boldsymbol{\Theta}$, control (no insulin). Each point is the mean result for duplicate plates.

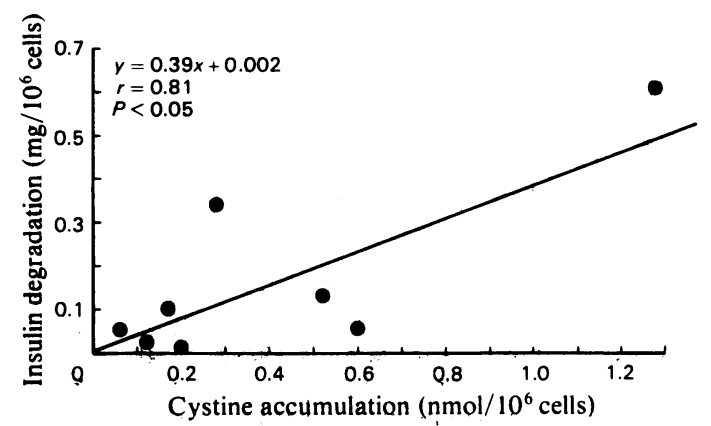

Fig. 2. Correlation between ${ }^{125}$ I-labelled insulin degradation and cystine accumulation by cultures of cystinotic fibroblasts

Data points are means of results for duplicate plates and are derived from experiments performed as described in Fig. 1 .

cystine $/ \mathrm{h}$ per $10^{6}$ cells. The effect of cysteine on cystine accumulation in these cells was determined by addition, to cystine-containing medium, of

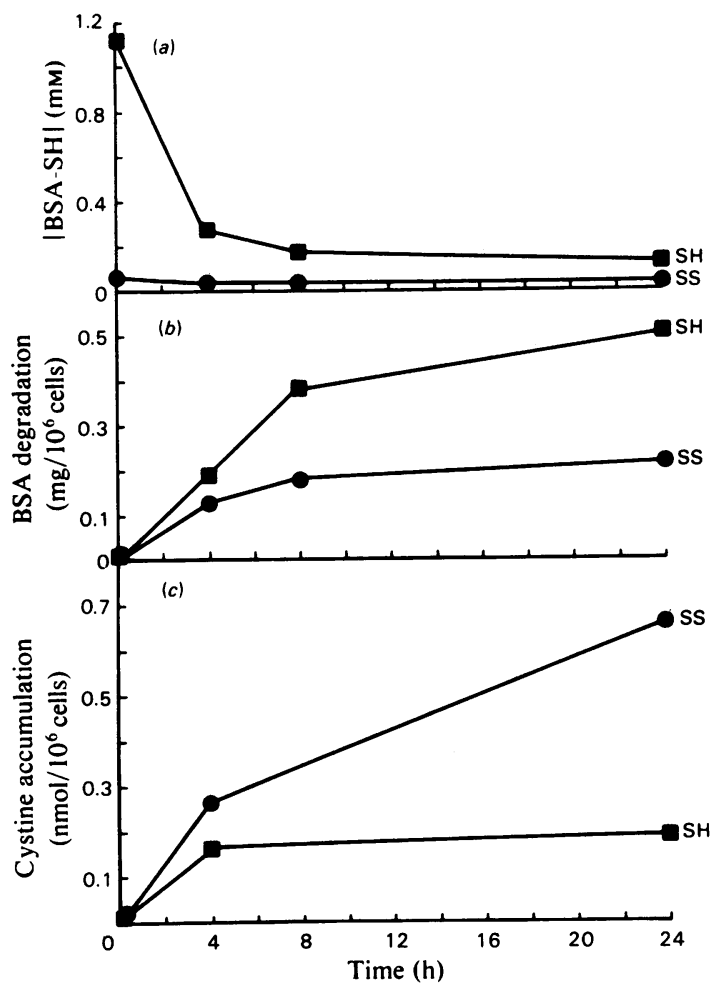

Fig. 3. Effect of reduced (BSA-SH) and native (BSA) bovine serum albumin on cystine accumulation

Reduced albumin was prepared by treatment with $0.3 \mathrm{M}$-mercaptoethanol in $6 \mathrm{M}$-urea for $2 \mathrm{~h}$, followed by $48 \mathrm{~h}$ dialysis under $\mathrm{N}_{2}$. Reduced and native albumin labelled with ${ }^{125}$ I was added to cultures of cystinotic fibroblasts in cystine-free serum-free medium. The rate of oxidation of the reduced albumin was monitored by reaction with Ellman's reagent $(a)$. The rate of protein degradation was determined by measuring the appearance of acidsoluble ${ }^{\mathrm{i} 25} \mathrm{I}$ in the culture medium $(b)$. Intracellular free cystine accumulation was measured by the cystine-binding-protein assay $(c)$.

reducing agents that do not themselves lead to cystine depletion. Both GSH and thiol-conjugated agarose fulfil this criterion. GSH at $2 \mathrm{mM}$ will rapidly reduce cystine to cysteine in tissue-culture medium containing $133 \mu_{\mathrm{M}}$-cystine. The half-time for this reaction is 20 min (results not shown). The effect of the addition of these two reducing agents on cystine reaçcumulation in cystine-depleted cystinotic fibroblasts is shown in Table 2.

After $5 \mathrm{~h}$ incubation in medium containing $133 \mu \mathrm{M}$-cystine and $1 \mathrm{mM}$-thiol-agarose or $2 \mathrm{mM}$ GSH, the thiol-treated cells had accumulated only 21 and $50 \%$ respectively of the amount of cystine accumulated by control cells not exposed to reductant. Incorporation of label into the GSH and 

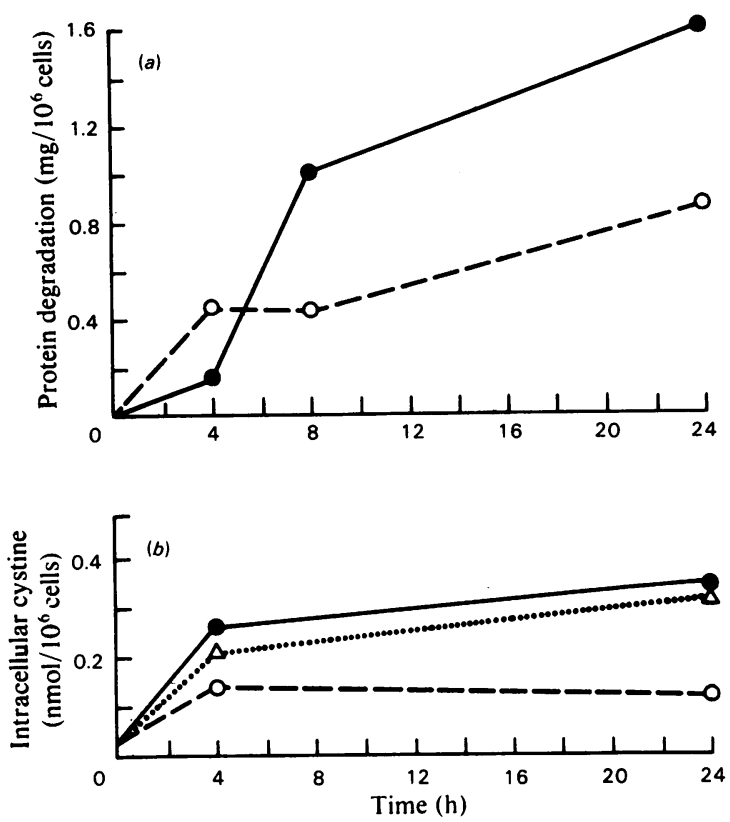

Fig. 4. Effect of ${ }^{125}$ I-labelled bovine serum albumin and ${ }^{125}$ I-labelled ovalbumin on cystine accumulation in cystine-depleted cystinotic fibroblasts

Bovine serum albumin $(10 \mathrm{mg} / \mathrm{ml}$; sp. radioactivity $1.31 \times 10^{5}$ c.p.m. $\left./ \mathrm{mg}\right)(O)$ and ovalbumin $(25 \mathrm{mg} /$ $\mathrm{ml}$; sp. radioactivity $5.32 \times 10^{4}$ c.p.m. $/ \mathrm{mg}$ ) (O) were added to cultures of cystine-depleted cystinotic fibroblasts. The cells were harvested at the intervals shown and the cystine content $(b)$ was measured by the cystine-binding protein assay. Protein degradation (a) was determined by the increase in acidsoluble radioactivity present in the culture medium at each time point. Control cells not treated with any protein are represented by $\triangle$

protein pools was the same in thiol-treated and control cells, indicating no toxicity due to these agents during this interval. Experiments in which these agents were added to control cells showed no cystine depletion after incubations of $8-10 \mathrm{~h}$. The greater relative amount of cystine recovered in the GSH-treated cells as opposed to the thiol-agarosetreated cells may be due to the effect of GSHcystine mixed disulphide formed in the medium $(0.6 \mathrm{mM}$ as measured by high-voltage electrophoresis of labelled compounds). Jonas et al. (1982) have shown greatly enhanced cystine loading of normal and cystinotic lysosomes by addition of this mixed disulphide to the culture medium. The difference in total amount of cystine accumulated in the two experiments is the result of variability in the rate of cystine accumulation, which has been previously described (Oshima et al.. 1976: States et

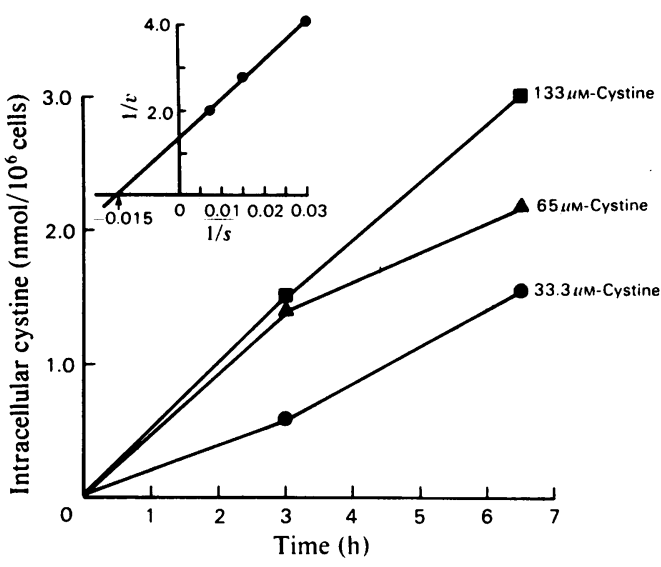

Fig. 5. Effect of various concentrations of free cystine on the re-accumulation of cystine within cystinotic fibroblasts

Cystine-depleted cells were prepared as previously described in the Experimental Section and placed in media containing the indicated concentration of free cystine and lacking foetal-calf serum supplementation. Cells were harvested at the times indicated and the intracellular cystine content determined by the cystine-binding-protein assay.

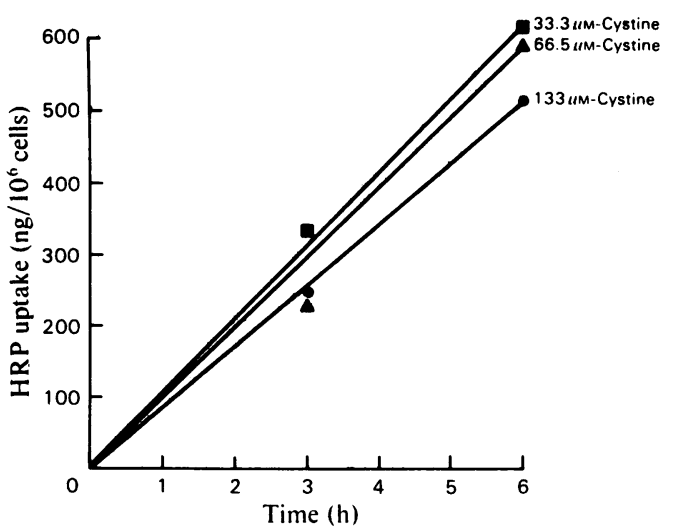

Fig. 6. Uptake of horseradish peroxidase (HRP) by, cystinotic fibroblasts incubated in three concentrations of cystine-containing medium

All media contained $1 \mathrm{mg} / \mathrm{ml}$ of horseradish peroxidase. At the times indicated the cells were harvested, the intracellular horseradish peroxidase content measured by the $o$-dianisidine method. and the intracellular cystine content measured by the cystine-binding-protein assay.

al.. 1981), and may also be due to dilution of the specific radioactivity of intracellular ${ }^{35} S \mid c y s t i n e$ by unlabelled cystine released from protein catabolism.

The contribution of pinocytosed cystine to total cell (lysosomal) cystine accumulation was de- 
Table 2. Effect of free cysteine on cystine accumulation

Cystinotic fibroblasts were seeded into $35 \mathrm{~mm}$ tissue-culture clusters (Costar) or $60 \mathrm{~mm}$ tissue-culture plates (Corning), grown to semi-confluency, depleted of cystine as described in the Experimental section, and placed in test media. Thiolated agarose beads (Pierce Chemical Co.) were added to media to make the final thiol concentration $1 \mathrm{mM}$. GSH was added to media containing $\left.\mathrm{L}-{ }^{35} \mathrm{~S}\right]$ cystine $\left(1.73 \times 10^{6} \mathrm{c} . \mathrm{p} . \mathrm{m} . / \mathrm{ml}\right.$ : sp. radioactivity $1.33 \times 10^{4} \mathrm{c} . \mathrm{p} . \mathrm{m}$./ $\mathrm{nmol}$ ) to a final concentration of $2 \mathrm{mM}$. The unlabelled cells were harvested by trypsin treatment. and intracellular free cystine was assayed by the cystine-binding protein assay. Labelled cells were harvested in the same way and acid-soluble metabolites quantified by high-voltage electrophoresis on paper.

\begin{tabular}{|c|c|c|c|c|c|}
\hline \multirow{2}{*}{$\begin{array}{l}\text { Cystine in } \\
\text { medium }\end{array}$} & \multirow[b]{2}{*}{ Agarose-SH } & \multirow[b]{2}{*}{ Time (h) } & \multicolumn{3}{|c|}{ Cystine $\left(\mathrm{nmol} / 10^{6}\right.$ cells) } \\
\hline & & & 0 & 2.5 & 5.0 \\
\hline+ & - & & 0.17 & 0.82 & 2.05 \\
\hline+ & + & & 0.17 & 0.35 & 0.43 \\
\hline- & - & & 0.17 & 0.23 & 0.19 \\
\hline- & + & & 0.17 & 0.32 & 0.34 \\
\hline & GSH & & \multicolumn{3}{|c|}{$\left.{ }^{335} \mathrm{~S}\right]$ Cystine $\left(\mathrm{nmol} / 10^{6}\right.$ cells $)$} \\
\hline+ & - & & 0 & 0.25 & 0.40 \\
\hline+ & + & & 0 & 0.11 & 0.20 \\
\hline
\end{tabular}

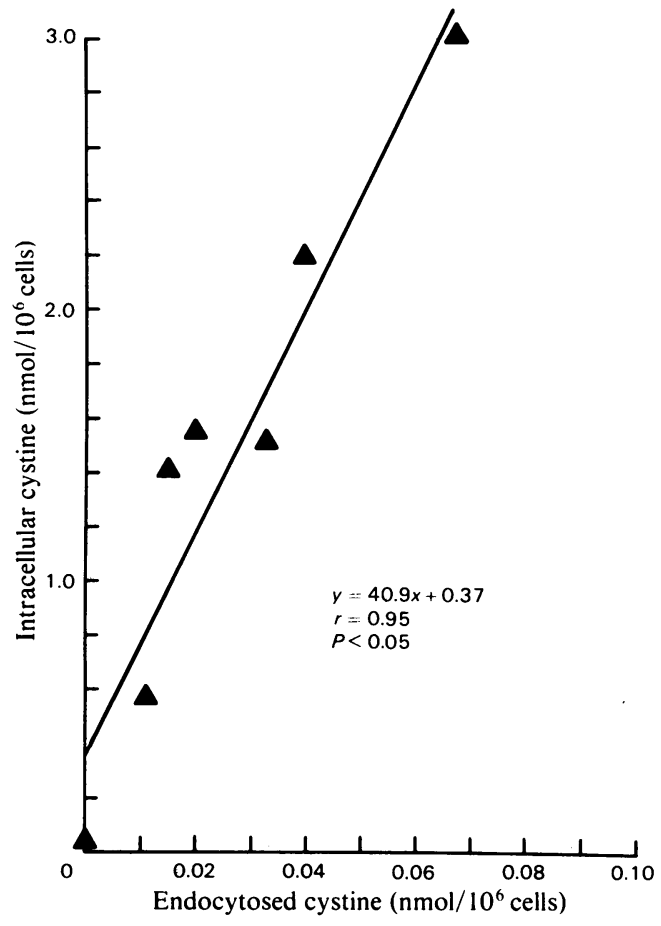

Fig. 7. Correlation between the amount of cystine endocytosed and total intracellular cystine accumulation Points were calculated from the known ratios of horseradish peroxidase and cystine in the culture medium as shown in Fig. 6.

termined in cystine-depleted cells by measuring the uptake of horseradish peroxidase in media of three cystine concentrations and simultaneously measur-
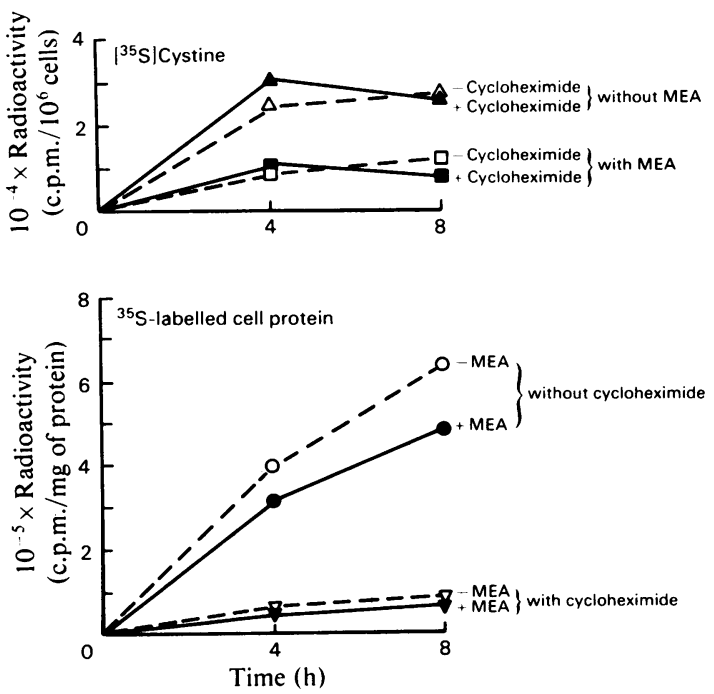

Fig. 8. Effect of $100 \mu \mathrm{M}$-cycloheximide on $\left[{ }^{35} S\right]$ cystine accumulation by cystinotic fibroblasts

Cystine-depleted cystinotic fibroblasts were incubated in $\left.{ }^{35} \mathrm{~S}\right]$ cystine-containing medium with and without the addition of $100 \mu \mathrm{M}$-cycloheximide and with and without prior cystine depletion by treatment with cysteamine (MEA). Cells were harvested by trypsin treatment at the times indicated and the distribution of label determined by one-dimensional high-voltage electrophoresis on paper.

ing the intracellular cystine content (Figs. 6 and 7). It is seen that the uptake of horseradish peroxidase is linear over the $6 \mathrm{~h}$ incubation period, and that decreasing the cystine content leads to a slight 
increase in horseradish peroxidase uptake. When the cystine contained in the volume of medium pinocytosed is compared with the amount of cystine recovered, it is seen that pinocytosed cystine accounts for only $1.5 \%$ of the total (Fig. 7).

Whether the rapid accumulation of cystine produced by free cystine (Fig. 5) occurs by passage through a protein pool was determined by measuring ${ }^{35}$ S $\mid$ cystine accumulation in medium with or without the addition of $100 \mu \mathrm{M}$-cycloheximide (Fig. 8). It can be seen that uptake of labelled cystine was not inhibited by cycloheximide in cystinotic cells, either with or without prior cystine depletion. Thus incorporation of cystine into a rapidly-turning-over protein pool does not appear to be responsible for a significant amount of cystine accumulation in these cells.

\section{Discussion}

The results of these investigations indicate that cystine, both free and as a component of proteins, can contribute to the lysosomal cystine pool but that cysteine, both free and protein-linked, does not. This finding is in agreement with the conclusions of Gahl et al. $(1982 a, b)$ that cystine is not reduced to cysteine before transport from normal lysosomes, and that the defect in cystinosis lies in failure, not of disulphide reduction, but rather of lysosomal transport of cystine. The finding that thiol-rich proteins inhibit the rate of cystine accumulation suggests that the defective transport system may be thiol-stimulated.

Since free cystine readily enters the lysosomal cystine pool (Fig. 5), then the question of the access route is raised. Cystinotic fibroblasts possess normal amounts of GSH (Oshima et al., 1976) and normal amounts of GSH reductase (Patrick, 1962). Therefore direct transit of cystine from the culture medium to the cytosol and hence to the lysosomal compartment would surely result in reduction of cystine to cysteine, precluding cystine accumulation. In the current work, two paths which could permit avoidance of reduction to cysteine were investigated. If the bulk of cystine were to remain in the micropinocytic vacuolar system, direct fusion of pinosomes and lysosomes could lead to lysosomal storage of cystine which had not been exposed to intracellular GSH. The data of Fig. 7, however, show that only a small fraction (about $1.5 \%$ ) of total cellular cystine can enter by this route. Another possibility is that free cystine could be incorporated into a protein pool with a short half-life. Lysosomal degradation of these disulphide-containing proteins could then permit entry of cystine into the lysosomal pool. Fig. 8 indicates that this is apparently not the case, since $90 \%$ inhibition of incorporation of $\left[{ }^{35}\right.$ S $\mid$ cystine into cellular protein had little or no effect on total $\left[{ }^{35}\right.$ S $]$ cystine accumulation.

These findings leave the route of access of free cystine to the lysosomal pool unexplained. We may propose, however, how cystinotic fibroblasts may serve in further investigation of the mechanism of proteolysis of disulphide-containing proteins. Kooistra et al. (1982) recently reported that the degradation of albumin and insulin by cathepsins D and $L$ is aided synergistically by the presence of thiol. Danpure (1981) showed fairly recently a paradoxical effect of chloroquine at low concentrations in enhancing the accumulation of cystine in cystinotic cells. The multiplicity of mechanisms involved in protein degradation are now being delineated (see Herschko \& Liechanover, 1982). The steps by which disulphide-containing proteins are degraded are not yet defined. Kooistra et al. (1982) suggest that partial proteolysis exposes disulphide bonds to reductant. Scission of these bonds may then permit further exposure of susceptible peptide bonds to proteolytic attack. It is not known if reduction of disulphide bridges occurs chiefly in the cytosol or within lysosomes. The data in the present paper demonstrate that some disulphide bonds in proteins must reach the lysosomal compartment unreduced to account for the enhanced lysosomal cystine accumulation produced by these proteins within cystinotic fibroblasts. Further exploration of the mechanism of lysosomal cystine accumulation from protein-linked cystine should lead to a greater understanding of these processes.

It is becoming apparent that the concept of lysosomes as a subcellular compartment containing hydrolases is over-simplified. Functional and anatomical distinctions between subpopulations of primary lysosomes and a variety of endosomes are now possible. Inhibitors of some functional characteristics of these organelles are now available. For example, pinocytosis is inhibited by monensin, which interferes with membrane recycling (Wilcox et al., 1982). Lysosomal acidification is known to be inhibited by $\mathrm{NH}_{4} \mathrm{Cl}$ and chloroquine. By using these agents in conjunction with cystinotic fibroblasts, it may become possible more clearly to define the site of protein disulphide reduction.

This work was supported by a grant (no. AM25548) from the U.S. National Institutes of Health. We thank Dr. Halvor Christensen for helpful critical comments, Dr. John Waterson and Dr. Peter Smouse for assistance with the statistical analysis, and Mrs. Phyllis Newberry for excellent secretarial assistance.

\section{References}

Danpure, C. J. (1981) Biochem.J. 200, 555-563

Gahl, W., Tietze, F., Bashan, N. \& Schulman, J. (1982a) J. Biol. Chem. 257, 9570-9575 
Gahl, W., Tietze, F., Bashan, N. \& Schulman, J. (1982b) Pediatr. Res. 16, 191A.

Herschko. A. \& Liechanover, A. (1982) Annu. Rev. Biochem. 51. 335-364

Jonas, A.. Greene. A.. Smith, M. \& Schneider. J. (1982) Proc. Natl. Acad. Sci. U.S.A. 79, 4442-4445

King. A., Hernaez-Davis. L. \& Cuatrecasas. P. (1980) Proc. Natl. Acad. Sci. U.S.A. 77. 3283-3287

Kooistra. T.. Millard. P. \& Lloyd. J. (1982) Biochem. J. 204, 471-477

Lowry, O. H., Rosebrough N. J., Farr, A. L. \& Randall, R. J. (1951) J. Biol. Chem. 193, 265-275

Oshima, R., Willis, R., Furlong, C. \& Schneider, J. (1974) J. Biol. Chem. 249, 6033-6039

Oshima. R.. Rhead. W., Thoene. J. \& Schneider. J. (1976) J. Biol. Chem. 251, 4287-4293
Patrick, A. D. (1962) Biochem. J. 83, 248-256

Schulman, J. D., Bradley, K. \& Seegmiller, J. (1969) Science 166, 1152-1154

States, B., Lee, J. \& Segal, S. (1981) Biochem. Biophys. Res. Commun. 98, 290-296

Steinman, R., Silver, J. \& Cohn, Z. (1974) J. Cell Biol. 63, 949-969

Thoene, J. \& Lemons, R. (1980a) J. Pediatr. 96. 1043-1044

Thoene, J. \& Lemons, R. (1980b) Pediatr. Res. 14. 785-787

Thoene, J., Oshima, R., Crawhall. J., Olson. D. \& Schneider, J. (1976) J. Clin. Invest. 58. 180-189

Thoene, J., Oshima, R., Richie, D. \& Schneider. J. (1977) Proc. Natl. Acad. Sci. U.S.A. 74. 4505-4507

Wilcox, D., Kitson, R. \& Widnell, C. (1982) J. Cell Biol. 92. 859-864 